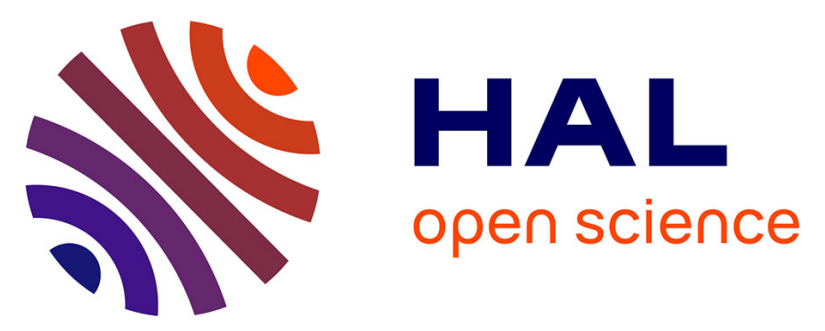

\title{
Increasing 3D Matrix Rigidity Strengthens Proliferation and Spheroid Development of Human Liver Cells in a Constant Growth Factor Environment
}

\author{
Jérémy Bomo, Frédéric Ezan, François Tiaho, Medjda Bellamri, Sophie \\ Langouët, Nathalie Théret, Georges Baffet
}

\section{To cite this version:}

Jérémy Bomo, Frédéric Ezan, François Tiaho, Medjda Bellamri, Sophie Langouët, et al.. Increasing 3D Matrix Rigidity Strengthens Proliferation and Spheroid Development of Human Liver Cells in a Constant Growth Factor Environment. Journal of Cellular Biochemistry, 2016, 117 (3), pp.708-720. 10.1002/jcb.25356 . hal-01196600

\section{HAL Id: hal-01196600 \\ https://hal-univ-rennes1.archives-ouvertes.fr/hal-01196600}

Submitted on 31 May 2016

HAL is a multi-disciplinary open access archive for the deposit and dissemination of scientific research documents, whether they are published or not. The documents may come from teaching and research institutions in France or abroad, or from public or private research centers.
L'archive ouverte pluridisciplinaire HAL, est destinée au dépôt et à la diffusion de documents scientifiques de niveau recherche, publiés ou non, émanant des établissements d'enseignement et de recherche français ou étrangers, des laboratoires publics ou privés. 
Increasing 3D matrix rigidity strengthens proliferation and spheroid development of human liver cells in a constant growth factor environment.

Jérémy Bomo ${ }^{1}$, Frédéric Ezan ${ }^{1}$, François Tiaho ${ }^{1}$, Medjda Bellamri ${ }^{1}$, Sophie Langouët ${ }^{1}$, Nathalie Theret $^{1}$ and Georges Baffet ${ }^{1}$

${ }^{1}$ Institut National de la Santé et de la Recherche Médicale (Inserm), UMR1085 Institut de Recherche sur la Santé l'Environnement et le Travail (IRSET), University of Rennes 1, SFR Biosit, F-35043 Rennes, France

*Running title: 3D matrix stiffness and liver cells phenotype

Correspondence should be addressed to: Georges Baffet, UMR 1085, IRSET, InsermUniversity of Rennes 1, Campus de Villejean, CS 34317, 35043 Rennes, France. Tel: (33)2.23.23.45.92. E-mail: georges.baffet@inserm.fr

Grant sponsors: Supported by Institut National de la Santé et de la Recherche Médicale (Inserm), Université de Rennes 1, Ligue contre le cancer du Grand Ouest, ANSES National EST-13-166 program and Région Bretagne; JB is a recipient of a fellowship from the Ministère de l'Enseignement Supérieur et de la Recherche and the Région Bretagne.

Figures: $7+2$ supplemental

Keywords:

Matrix stiffness, liver cells, proliferation, biotransformation 


\section{Abstract:}

Mechanical forces influence the growth and shape of virtually all tissues and organs. Recent studies show that increased cell contractibility, growth and differentiation might be normalized by modulating cell tensions. Particularly, the role of these tensions applied by the extracellular matrix during liver fibrosis could influence the hepatocarcinogenesis process. The objective of this study is to determine if 3D stiffness could influence growth and phenotype of normal and transformed hepatocytes and to integrate extracellular matrix (ECM) stiffness to tensional homeostasis. We have developed an appropriate 3D culture model: hepatic cells within three-dimensional collagen matrices with varying rigidity. Our results demonstrate that the rigidity influenced the cell phenotype and induced spheroid clusters development whereas in soft matrices, Huh7 transformed cells were less proliferative, well-spread and flattened. We confirmed that ERK1 played a predominant role over ERK2 in cisplatin-induced death, whereas ERK2 mainly controlled proliferation. As compared to $2 \mathrm{D}$ culture, $3 \mathrm{D}$ cultures are associated with epithelial markers expression. Interestingly, proliferation of normal hepatocytes was also induced in rigid gels. Furthermore, biotransformation activities are increased in 3D gels, where CYP1A2 enzyme can be highly induced/activated in primary culture of human hepatocytes embedded in the matrix. In conclusion, we demonstrated that increasing 3D rigidity could promote proliferation and spheroid developments of liver cells demonstrating that 3D collagen gels are an attractive tool for studying rigidity-dependent homeostasis of the liver cells embedded in the matrix and should be privileged for both chronic toxicological and pharmacological drug screening. 


\section{Introduction:}

Chronic liver diseases leading to Hepatocarcinoma (HCC) are associated with extracellular matrix (ECM) over-production. Studies in the field of Mechanical Biology have revealed that many cell behaviors for multi-step cancer formation can be influenced by physical interactions between cells and their ECM (Paszek et al., 2005; Paszek and Weaver, 2004). Cells in vivo are often surrounded by ECM and will encounter varying three-dimentional matrix environments and mechanical forces during wound healing fibrosis development. It is now accepted that insoluble factors, particularly components of the ECM, have equally essential roles as soluble mitogens and antimitogens in the proliferation/differentiation of many cell types. Soluble mitogens and ECM proteins jointly regulate activation of the $\mathrm{G} 1$ phase which is required for $S$ phase entry through the activation of MEK/ERK MAPKinases pathway in hepatic cells. Temporal activations/inhibitions are key determinants in generating precise biological responses (Frémin et al., 2012; Kholodenko et al., 2010). As a hallmark of ECM-cell interactions, the ability to sense extracellular stiffness and tissue stiffness/compliance, may be an important determinant of downstream dependent signaling events. These findings question basic assumptions in the field of cancer research, and raise the intriguing possibility that cancer development may be, up until a certain point, a potentially reversible disease that results from progressive disregulation of tissue architecture leading to physical changes in ECM/cells and altered mechanical signaling. This perspective raises the possibility of developing biologically-inspired materials that mimic microenvironment and that could be used to induce and reverse cell phenotype into cells and tissues. A pervasive model approach to the study of ECM function could be using cells cultured in substrat which mimic the rigidity of the extracellular environment that liver cells encounter in vivo.

Liver fibrosis is a wound-healing process leading to ECM deposit and formation of macroregenerative nodules, in response to various toxic injuries and associated with almost all chronic liver diseases (for review (Wallace et al., 2008)). Indeed, cirrhosis is characterized by macro-regenerative nodules (also referred as adenomatous hyperplastic nodules or dysplastic nodules) which correspond to premalignant lesions. These early malignant nodules are quite similar to large regenerative nodules and are under increasing mechanical stress. Once established, tumor development is associated with further increases in matrix stiffness. Prospective studies have shown the association between liver stiffness measurement by elastography and the risk of $\mathrm{HCC}$ development in patients with hepatitis (Masuzaki et al., 2009). It is now accepted that HCC develops and grows in a particular microenvironment surrounded by mechanical forces that could greatly affect the phenotype of liver cells. The role of the extracellular matrix stiffness in the process of 
hepatocarcinogenesis could therefore greatly influence cell fate and the balance between proliferation, differentiation, survival and motility. However, little is known about whether and how intracellular signalling pathways are activated by mechanical microenvironment in the liver during fibrosis and cirrhosis.

One of the key features of fibrotic/cirrhotic liver is the overabundance of collagen I fibers, the most abundant form of collagens in both normal and pathologic livers, mainly produced by activated stellate cells (Lee and Friedman, 2011). Collagen, is a readily available biomaterial which can be used in a 3D matrix model with varying stifness. In contrast to cells on twodimensional (2D) surfaces, 3D cultures require that cells adapt their morphology, phenotype, and migration to forces around the microenvironment surroundings. Cells can also interact with the ECM by an active remodeling of the matrix. This led us to develop a mechano-biochemical model to analyse experimentally the adaptive response of the hepatic cells to variations in stiffness of its extracellular environment. To test the link between stiffness and cell proliferation/survival, experiments have been done in vitro with liver cells cultured in collagen substrata with varying stiffness. In this study, we have developed and characterized a 3D collagen I model of stiffness that mimics the fold increase and some properties of in vivo ECM stiffening during fibrosis. Rheometry was used to measure the elastic modulus; Two-PhotonExcited-Fluorescence microscopy (TPEF) was used to image proliferative liver cells; and Second Harmonic Generation (SHG) was used to quantify collagen I and visualize fibril orientations. Depending on different collagen gel stiffness, the phenotype of transiently and long term normal and transformed liver cells have been analyzed by looking at the capacity of the cell to progress in the cell cycle, survive and differentiate. As extracellular substrates with easily tunable stiffness properties, 3D type I collagen gels provide valuable flexible media for studying in vitro the dynamical response of liver cells responding to variations in stiffness. This goal led us to experimentally analyse the adaptive response of the liver cells to stiffness variations of its 3D extracellular microenvironment.

This approach allowed us to establish that rigidity greatly influences the phenotype of hepatocytes embedded in the matrix when compared to 2D cultures. Important differences are certified when different forces are applied and increasing matrix stiffness emphasizes both proliferation and differentiation whereas EMT is more accentuated in soft gels and 2D cultures. Furthermore, we demonstrated that proliferation is under a MAPK MEK1/2-ERK2 dependent mechanism. 


\section{Materials and Methods:}

\section{Cell culture and reagents}

Human Huh7D12 (Huh7) hepatocarcinoma cell line (Health Protection Agency Culture Collections, n॰01042712) were grown in DMEM 4.5g/L glucose containing penicillin (100 $\mathrm{IU} / \mathrm{ml}$ )-streptomycin $(100 \mu \mathrm{g} / \mathrm{ml})$ and supplemented with $10 \%$ foetal calf serum (FCS). F1 biliary epithelial cells were obtained from the liver of a 10-day-old Fischer rat (Morel-Chany et al., 1978). F1 cells were grown in William's E Medium without L-Glutamin containing penicillin $(100 \mathrm{IU} / \mathrm{ml})$-streptomycin $(100 \mu \mathrm{g} / \mathrm{ml})$ and supplemented with $7.5 \mathrm{FCS}$. Rat hepatocytes were isolated and purified from rat liver by in situ perfusion with highly active purified collagenase Liberase (Roche, Meylan, France), as previously described (GuguenGuillouzo, 2002). Rat hepatocytes were cultured in $75 \%$ minimum essential medium (MEM), and $25 \%$ medium 199 , supplemented with penicillin (100 IU/ml), streptomycin $(100 \mu \mathrm{g} / \mathrm{ml})$, insulin $(5 \mu \mathrm{g} / \mathrm{ml})$, bovine serum albumin $(1 \mathrm{mg} / \mathrm{ml})$, glutamine $(2 \mathrm{mM})$ and $5 \% \mathrm{FCS}$, and after $24 \mathrm{~h}$ medium was supplemented with $1.4 \times 10^{-7} \mathrm{M}$ of hydrocortisone hemisuccinate and 50ng/ml EGF (Frémin et al., 2012). Human liver samples were obtained from patients undergoing liver resection for primary hepatocellular carcinomas or metastatic livers through the Centre de Ressources Biologiques (CRB)-Santé of Rennes (CHRU Pontchaillou, Rennes, France). The research protocol was conducted under French legal guidelines and the local institutional ethics committee. Human hepatocytes were isolated by a two-step collagenase perfusion procedure, and parenchymal cells were maintained in Williams' modified medium supplemented with EGF (50 ng/ml), HGF (10 ng/ml) and 1.4×10-7M hydrocortisone hemisuccinate (Andrieux et al., 2004).

Reagents: 3-(4,5-Dimethylthiazol-2-yl)-2,5-diphenyltetrazolium bromide (MTT), Propidium lodide (PI) and Hoechst were from Sigma-Aldrich (St-Quentin-Fallavier, France). Cell proliferation Reagent WST-1 was from Roche (Meylan, France). The Cisplatin was from Mylan (Saint-Priest, France), MROD and EROD from Sigma. The MEK inhibitors U0126 and EGF were from Promega (Charbonnières, France), the MLCK inhibitor ML7 was from Sigma-Aldrich (St-Quentin-Fallavier, France) and the ROCK inhibitor Y-27632 was from Calbiochem (VWR, Fontenay-sous-Bois, France). Antibodies against phospho-ERK1/2 (Thr202/Tyr204), Puma, Bid, Bax, Paxillin and E-cadherin were purchased from Cell Signaling (Ozymz, Saint-Quentin-enYvelyne, France). Anti-human Noxa was from Calbiochem (WWR, Fontenay-sous-Bois, France). Polyclonal antibodies against ERK1 (sc-94), ERK2 (sc-154) and hsc-70 (sc-7298) were from

Santa Cruz Biotechnology (Tebu-bio, Le-Perray-en-Yvelines, France). Anti-vimentin and secondary antibodies conjugated to horse-radish peroxidase were obtained from Dako 
(Trappes, France). Secondary antibodies coupled with Alexa Fluor were from Becton Dickinson (BD Biosciences, San Jose, CA)

\section{Collagen $3 D$ culture}

To include cells in 3D collagen gels, Type I collagen from Sigma-Aldrich (St-Quentin-Fallavier, France) at $3 \mathrm{mg} / \mathrm{ml}$ is diluted with culture medium to obtain a collagen solution of $0.75 \mathrm{mg} / \mathrm{ml}$ and $1.5 \mathrm{mg} / \mathrm{ml}$. At the same time, the cells were added at a concentration of $125.10^{3}$ cells $/ \mathrm{ml}$ to this solution, and the $\mathrm{pH}$ was adjusted to 7.4 by $\mathrm{NaOH} 0.01 \mathrm{~N}$. This mix of cells and collagen was poured into 96 -well plates $(100 \mu \mathrm{L})$ or 24 -well plates $(400 \mu \mathrm{L})$ and incubated at $37^{\circ} \mathrm{C}$. After 10 minutes, the gels were polymerized and an equal volume of medium was added.

\section{SHG microscopy}

The SHG imaging system is composed of a confocal TCS SP2 scanning head (Leica Microsystems, Mannheim, Germany) mounted on a DMIRE2 inverted microscope (Leica Microsystems) and equipped with a MAITAI femtosecond laser (Spectra Physics, Santa Clara, CA). A 10X dry objective (NA=0.4; Leica Microsystems) and 60X water immersion (Olympus LUMFL $60 \mathrm{~W} \times 1.1 \mathrm{NA}$ ) was used for applying an $820-\mathrm{nm}$ excitation to the sample. The SHG signal was collected in the forward direction using the condenser $(\mathrm{S} 1, \mathrm{NA}=0.9-1.4$; Leica Microsystems), and the TPEF was epi-collected in the backward direction. IRSP 715 bandpass and 410-nm infrared (IR) filters (10-nm full width at half-maximum, FWHM) were placed before the photomultiplier tube. The image processing was performed with imageJ software (National Institutes of health; http://rsb.info.nih.gov.gate2.inist.fr/ij/).

\section{Rheometry}

Rheometry was used to determine the stiffness of collagen gels with a Kinexus (Malvern, Orsay, France). Gels were synthetysed in 12-well plates with a volume of $1.2 \mathrm{ml}$ to have a thickness of $3 \mathrm{~mm}$. A round turntable with a diameter of $2 \mathrm{~cm}$ crushed the gel to a height of $0.5 \mathrm{~cm}$. This turntable applied oscillation at a frequency of $0.1 \mathrm{~Hz}$ as well as shear stress ranging from $0.02 \mathrm{~Pa}$ to $2 \mathrm{~Pa}$. The elastic and viscous modulus were obtained in the constant part of the curve.

\section{Cells staining}

For TPEF observation, cells were stained with DiA 10 $\mathrm{g} / \mathrm{ml}$ (Interchim, Montluçon, France) overnight prior to being included in gels and observed with SP2 microscope.

For confocal observation, after fixation in formol $4 \%$, cells were permeabilized with $0.1 \%$ Triton $\mathrm{X}-100$. After saturation with $2 \%$ bovine serum albumin for $1 \mathrm{H}$ at room temperature, cells were stained. To see actin, Phalloidin-Fluoprobes $457 \mathrm{H}$ (Interchim) 66nmol/L and 
Hoechst $5 \mu \mathrm{g} / \mathrm{ml}$ were used. For immunostaining, cells were incubated with anti-Paxillin (1:500, Cell Signaling) in BSA $1 \%$ at $4^{\circ} \mathrm{C}$ overnight. After, a secondary antibody coupled with Alexa Fluor 488 was incubated $1 \mathrm{H}$ at room temperature. After being washed, the nuclei were stained with Hoechst. Cells were observed with a LEICA DMI 6000 CS SP8 microscope (Leica Microsystems).

\section{Collagen gels inclusion in paraffin}

After fixation, (formol 4\%) collagen gels were dehydrated with successive increasing concentrations of alcohol and Xylene baths before being impregnated with paraffin using EXCELSIOR ES tools (Thermo Scientific, Waltham, USA) and left overnight. After impregnation, gels were included in paraffin blocs and $4 \mu \mathrm{m}$ cuts were made. Immunostainings were done with Ventana Discovery XT tools and the Ventana DABMap detection kit (Ventana Medical Systems, Tucson, Arizona). Slides were observed with a Nanozoomer NDP slide scanner (Hamamatsu, Massy, France).

\section{Viability assays}

For viability assays, cells were seeded in 96-well plates in 2D or 3D. After the time of culture or treatment indicated an MTT or WST1, assays were performed. Briefly, cells were incubated with $0.5 \mathrm{mg} / \mathrm{ml}$ of $\mathrm{MTT}$ for $2 \mathrm{~h}$ at $37^{\circ} \mathrm{C}$. For the $3 \mathrm{D}$ cells, gels were degraded by a Liberase solution $(8 \mu \mathrm{g} / \mathrm{m})$ for twenty minutes, then the cells were pelleted by centrifugation to eliminate the Liberase. After, cells were lysed by dimethyl sulfoxide and the absorbance was measured at $540 \mathrm{~nm}$ on Spectrostarnano (BMG Labtech, Champigny sur Marne, France). For the WST1 viability assay, the WST1 stock solution was diluted 10 fold and incubated with the cells at $37^{\circ} \mathrm{C}$ for $1 \mathrm{~h}$. The absorbance was measured at $430 \mathrm{~nm}$.

\section{$\left[{ }^{3} H\right]$ Thymidine incorporation}

The rate of DNA synthesis in cells was measured by adding $2 \mu \mathrm{Ci}$ of [methyl- ${ }^{3} \mathrm{H}$ ] thymidine (Amersham, Buckinghamshire, UK) during $24 \mathrm{H}$. After the incubation, an ice-cold trichloroacetic acid $(30 \%)$ was used to precipitate the DNA. In parallel, a MTT assay was performed to normalize thymidine incorporations.

\section{Necrosis study}

Necrotic cells are determined by a double staining with Hoechst $5 \mu \mathrm{g} / \mathrm{ml}$ and Propidium lodide $5 \mu \mathrm{g} / \mathrm{ml}$. The doubled stained nucleus corresponding to necrotic cells are counted and mean percentages of necrotic cells are reported. 


\section{Caspase-3/7 activity}

For cisplatin-induced hepatotoxicity experiments, caspase $3 / 7$ activity was measured by the 'SensoLyte Homogeneous AMC Caspase-3/7 Assay' kit (Anaspec, Le-Perray-enYvelines,France) following manufacturer's instructions. Briefly, the cells were lysed in a 96-well plate (for 3D after gel degradation by Liberase) and the caspase-3/7 substrate solution (DEVDAMC) was incubated with the cell lysates for one hour at $37^{\circ} \mathrm{C}$. AMC cleavage was monitored by spectrofluorometry (Vmax). As cells were directly lysed in the plate, MTT assays were performed in parallel to normalize the Vmax to an approximation of viable cells.

\section{Measurement of P450 Activities}

Ethoxyresorufin O-deethylation (EROD) associated with P450 1A1/2 activity was measured in cultured hepatocytes, essentially as described by Burke and Mayer (Burke and Mayer, 1983). Methoxyresorufin O-demethylation (MROD) was used as a substrate for specific P450 1A2 activity. After the lecture of activities, a WST-1 test was done to normalize activity with the viable cells.

\section{Western blot}

Extracts from Huh7 or F1 cells were separated using SDS-PAGE. Proteins were transferred to nitrocellulose menbranes in a transfer buffer (25mM Tris, $200 \mathrm{mM}$ glycine and ethanol $20 \%$ ). Membranes were blocked in $5 \%$ low fat milk in tris-buffer saline (TBS) (65mM Tris $\mathrm{pH} 7,4$, $150 \mathrm{mM} \mathrm{NaCl}$ ) for one hour at room temperature. Membranes were incubated with primary antibodies overnight at $4^{\circ} \mathrm{C}$. After being washed with TBS, appropriate secondary antibodies linked to horseradish peroxidase were incubated for one hour in 5\% low fat milk in TBS at room temperature. Immunocomplexes were visualized with Ommobilon Western Chemiluminescent HRP substrate (Millipore) and scanned with a Fujifilm LAS-3000 imager (Fujifilm, Tokyo, Japan). Densitometric analyses of the bands were carried out with MultiGauge software (Fujifilm).

\section{Reverse transcription and polymerase chain reactions}

Total RNA was extracted from cultured cells using NucleoSpin RNA (Macherey-Nagel, Hoerdt, France). The concentration of total RNA-XS was measured with a NanoDrop ND-1000 (NanoDrop Technologies). Reverse transcription was performed with the High Capacity cDNA reverse transcriptase kit (Applied Biosystems, Saint Aubin, France). Real-time quantitative PCR for all genes was performed using SYBR green methodology with the Power SYBR Green PCR master mix (Applied Biosystems) and the ABI 7000 Sequence Detector System (Applied Biosystems) according to the manufacturer's instructions. 
Primers for human N-cadherin cDNA were 5'-GTGCATGAAGGACAGCCTCT-3' (forward) and 5'-ATGCCATCTTCATCCACCTT-3' (reverse), E-cadherin 5'-TGCTCTTGCTGTTTCTTCGG-3' (forward) and 5'-TGCCCCATTCGTTCAAGTAG-3' (reverse), Vimentin 5'CCAAACTTTTCCTCCCTGAACC-3' (forward) and 5'-GTGATGCTGAGAAGTTTCGTTGA-3' (reverse), Cytokeratin 8 5'-AGCTGGAGTCTCGCCTGGAA-3' (forward) and 5'TGTGCCTTGACCTCAGCAATG-3' (reverse), and Cytokeratin 18 5'GAGCCTGGAGACCGAGAAC-3' (forward) and 5'-TTGCGAAGATCTGAGCCC-3' (reverse).

Primers for rat Albumin were 5'-CTGACACCGAAGCTTGATGC-3' (forward) and 5'GACAGCTGCGACCAGTGCT-3' (reverse), Aldolase B 5'-ACAGCTTCTGATACCTTGGAGCA3' (forward) and 5'GATGACAGGTACAGCCAAGGG-3' (reverse), and GST a2 5'CATCGCCAAATATGACCT-3' (forward) and 5'-AGGGCTCTCTCCTTCATGTCC-3' (reverse). The amplification curves were read with ABI Prism 7000 SDS software using the comparative cycle threshold method. Relative mRNA levels were calculated after normalization with $18 \mathrm{~S}$ RNA.

\section{Cell transfection}

Transcient transfections with shERK1 and shERK2 were obtained using the protocol previously described (Guégan et al., 2013). Briefly, DNA transfections were carried out using Lipofectamine RNAi max transfection reagent (Invitrogen, Saint Aubin, France) according to the manufacturer's instructions. Cells were plated in a $35 \mathrm{~mm}$-petri dish. After overnight incubation, pBABE-puro vector $+1 \mu \mathrm{g}$ of expression plasmid were mixed with $5 \mu$ l of Lipofectamine RNAi max and then added to the cells. Cells were selected for 24 hours by puromycin $(4.5 \mu \mathrm{g} / \mathrm{ml})$ and cyclosporine $(5 \mu \mathrm{M})$ as described (Lefloch et al., 2008).

\section{Statistical analysis}

Results are expressed as the mean \pm standard deviation. Data were analyzed with two-tailed Student's $t$-test. Differences were considered significant when $P<0.05\left({ }^{*}\right), \quad P<0.01\left({ }^{* *}\right)$, $\mathrm{P}<0.005\left(^{* * *}\right)$. All experiments were performed at least three times. 


\section{Results:}

\section{Increased collagen gel concentration induces 3D stiffness.}

Multiphoton microscopy has been widely used for imaging structure and dynamic interactions in biological cells and tissues with higher sub-micron resolution (Chen et al., 2012). Among these methods, SHG imaging method shares many of the features of two photon excitation fluorescence microscopy (TPEF). SHG permits, in unstained samples, the assessment of supramolecules with high crystalline triple-helix structures deprived of centrosymetry at microscopic and mesoscopic scales as fibrillar collagen (Campagnola et al., 2002; Gauderon et al., 2001a, 2001b; König, 2000; Zipfel et al., 2003). As illustrated, figures 1A and 1B show images of collagen I gels of $0.25,0.5,0.75,1,1.5$ and $2 \mathrm{mg} / \mathrm{ml}$. These images show highly uniform and smooth, randomly oriented, nanofibers. The collagen fibrils are typically not closely packed and are spaced in loose areas between fibrils. We were able to detect smaller pores and higher fiber lengths in more concentrated gels, as might be expected when a given volume contains a higher numbers of fibers (figure 1C). Fiber diameter did not change with the gel concentration, however, fiber length increased. Gel rigidity was further characterized by rheometry (Figure 2A). A direct proportional relation was found between collagen concentrations and the elastic $\left(G^{\prime}\right)$ and viscous modulus $\left(G^{\prime \prime}\right)$ with an exponential curve $\left(Y=0.1411 e^{2.346 x}\right.$; $R^{2}=0.9441$ for $G^{\prime}$ and $Y=0.03853 e^{2.222 x} ; R^{2}=0.9303$ for $\left.G^{\prime \prime}\right)$. As expected, rigidity highly increased with the collagen concentrations, consistent with other reports showing mechanical properties of nanofibrous scaffolds to be highly dependent on nanofiber concentration (see figure $2 \mathrm{~A}$ and table in supplemental figure $1 \mathrm{~A}$ ). A comparison between compliant and rigid gels seems to be a good model to mimic the effect variations of stiffness have on the morphology and phenotype of hepatic cells allowed to grow and survive in the matrix. According to these observations, we choose to work with two collagen concentrations which produce reproducible and well defined working gels i.e. $0.75 \mathrm{mg} / \mathrm{ml}(1 \mathrm{~Pa}=$ compliant gel $)$ and $1.5 \mathrm{mg} / \mathrm{ml}(3.5 \mathrm{~Pa}=$ rigid gel). This fold increase rigidity, $3.5 x$ between collagen gels of 0.75 and $1.5 \mathrm{mg} / \mathrm{ml}$, is closed to the one measured in the liver in vivo during fibrosis development (Lupsor Platon et al., 2013).

\section{Matrix rigidity influences spheroid formation of human hepatocellular carcinoma cells.}

To explore whether matrix rigidity influences cellular behavior, we seeded transformed human hepatocarcinoma cells (Huh7) in compliant $1 \mathrm{~Pa}$ and rigid $3.5 \mathrm{~Pa}$ gels. Huh7 cells appeared well-spread in soft compliant collagen gels $(1 \mathrm{~Pa})$ and formed monolayer-like structures with flattened shapes. In contrast, in rigid gels (3.5 Pa) cells were non-spread and formed rapidly 
spherical clusters that increase along the culture time as observed by phase contrast and TPEF microscopies at days 3, 6 and 10 after seeding (figure 2A). Differences in cellular spreading, as a function of support stiffness is already observed, at higher magnification, one day after seeding (figure 2B). Cells did not spread in rigid matrices and this typical morphology of round cells was strengthened during the culture period, becoming muti cellular spheroids between day 3 and 6 in $3.5 \mathrm{~Pa}$ gels (figure 2A). We extend our results to another transformed liver cell line, the F1 biliary epithelial cells, and show that cell spheroid organisation in rigid gels is not limited to Huh7. Indeed, in 3.5 Pa collagen gels, F1 cells also grow in spheroids, whereas cells are flattened and spread out in $1 \mathrm{~Pa}$ gels (data not shown).

In order to look at the cluster organisation of these spheroids, we performed 3D confocal imaging (figure $3 \mathrm{~A}$ ) and Heamatoxilin-Eosin staining of thick sections (figure $3 \mathrm{~B}$ ) of embedded spheroids in collagen gels. Z-stack reconstructions of spheroids in the three dimensions (xyz) show acini-like structures with hollow lumen. This particular organisation is also clearly visible on Heamatoxilin-Eosin thick sections of spheroids (figure 3B). Note that between day 1 and day 8 of culture, cell surface areas decreased by $50 \%$ in $3,5 \mathrm{~Pa}$ cultures, whereas the area of the nucleus remained unchanged (supplemental figure 1B).

In order to look at cell plasticity in 3D gels and if mechanical remodeling of matrix and cell behaviours could be modulated during culture times, matrix of 6 days-cultured cells ( $1 \mathrm{~Pa}$ and 3.5 Pa gels) were released from the culture dishes by mechanical unsticking of the gels from the dishes by sterile tips. Cell morphology and cell-mediated contraction of gels were analyzed after releasing. First, as we could expected, we observed a cell-mediated contraction of the collagen gels after releasing, during the culture time, begining at day 2 and 3 after releasing, higher in 1 $\mathrm{Pa}$ than in 3.5 Pa gels (see figure $3 \mathrm{C}$ or for quantification supplemental figure $1 \mathrm{C}$ ). Markedly, 2 days after releasing, cells initialy flatted in $1 \mathrm{~Pa}$ gel, have adopted a spherical cluster morphology whereas in unreleased $1 \mathrm{~Pa}$ gels, the cells remained flatted and spreaded (figure $3 \mathrm{C}$, c versus a). As control, no morphological modification could be seen in $3.5 \mathrm{~Pa}$ gels after releasing (figure $3 \mathrm{C}$, $\mathrm{d}$ versus $\mathrm{b}$ ). This experiment demonstrated a cell plasticity, from flattened to speroid morphology, simultaneously to gel contraction.

\section{Rigidity increases survival and proliferation.}

We first quantified cell survival/proliferation by MTT assays in 3D cultures. $2 \mathrm{D}$ cultures were used as external control. Indeed, normal and transformed hepatic cells are well-spread and highly proliferative when cultured on plastic or collagen film (Bessard et al., 2008; Frémin et al., 2009; Hansen et al., 2006; Schrader et al., 2011). Our results show a significant increase of MTT activity in rigid collagen gels (figure 4A). Afterwards, we studied the proliferation capability of these $3 \mathrm{D}$ cultured cells using methyl-thymidine $\mathrm{H}^{3}$ incorporation. Throughout the entire 
process, the proliferation of Huh7 cells in the collagen gels is higher compared to $2 \mathrm{D}$ cultures (figure 4B). Moreover, the methyl-thymidine $\mathrm{H}^{3}$ incorporation is highly increased in rigid matrix compared to compliant gels during the first 3 days after cell seeding.

Because the MEK-ERK pathway is required for cell proliferation of liver cells (Bessard et al., 2008; Frémin et al., 2007), we next investigated ERK phosphorylation and inhibition in our models. As already shown in $2 \mathrm{D}$ cultures, phosphorylation of ERK1/2 was also induced by FCS+EGF in gels (supplemental figure 2A). As expected, MEK inhibitor U0126 completely abolished ERK1/2 phosphorylation and greatly decreased Huh7 cell proliferation in compliant and rigid gels (figure 4C). In addition, the specific silencing of ERK1 or ERK2 in the 3D models (figure 4D) confirms that proliferation was under an ERK2-dependent mechanism in 3D gels. ERK1 silencing did not affect the replication level of the cells, as previously described (Bessard et al., 2007; Frémin et al., 2009; Gailhouste et al., 2010; Guégan et al., 2013, 2012).

Interestingly, only low basal levels of necrotic and apoptotic cells can be detected in 3D cultures (figure $5 \mathrm{~A}$ and $5 \mathrm{~B}$ ). As expected, caspase $3 / 7$ activities increased after cisplatin treatment at 1 and $10 \mu \mathrm{g} / \mathrm{ml}$, and no difference could be obtained between cells in compliant and rigid gels as compared to $2 \mathrm{D}$ cultures (figure $5 \mathrm{C}$ ). Only a partial protection could be detected in rigid gels after cisplatin treatment (figure 5D). These apoptotic inductions by the cisplatin were prevented by ERK1/2 inhibition (Figure 5E), as observed after 24 hours of co-treatment with cisplatin and U0126, independently of matrix stiffness. We recently demonstrated that ERK1 silencing could protect cells from cisplatin-induced apoptosis (Guégan et al., 2013). Note that, at a high concentration of cisplatin $(40 \mu \mathrm{g} / \mathrm{ml})$, independent of stiffness, apoptosis can be partially prevented by ERK1 inhibition, as compared to shControl and shERK2 cells (figure 5F). In our $3 \mathrm{D}$ culture conditions, we were also able to detect a high level of expression of the pro-apoptotic factor Noxa in ERK2 inhibited cells when compared to shERK1 silenced cells (supplemental figure $2 \mathrm{~B}$ ) confirming the previous data indicating that ERK1 could be responsible for cisplatininduced Noxa up-regulation in 2D cultured hepatic cells (Guégan et al., 2013).

\section{3D cultures are associated with epithelial markers expression of Huh7 liver cells.}

Because EMT could be highly dependent on mechanical force variations, we analyzed the epithelial and/or mesenchymal "like status" of Huh7 cells cultured in soft and stiff gels. Examination of some EMT markers by qPCR and western blotting indicated that $3 \mathrm{D}$ cells express higher levels of epithelial markers than mesenchymal markers, as compared to 2D cultured cells (Figure 6A). N-cadherin mRNA expressions are lower in 3D cells and the same results were obtained at the protein level for vimentin (figure $6 \mathrm{~B}$ ). Conversely, E-cadherin expressions at the mRNA and protein levels were more highly expressed in 3D cells as 
compared to these levels in 2D cultures, and no significant difference can be observed between compliant and rigid gels. Immunolocalisations of $\mathrm{N}$ and E-cadherins between cells and/or around the lumen confirmed an epithlial status of the Huh7 cells in 3D rigid matrix (figure 6C). As control, cytokeratin 8 and 18 expressions, which are highly induced during 2D liver cell cultures (Baffet et al., 1991; Moll et al., 1982) were highly reduced in cells cultured in 3D gels as compared to 2D (Figure 6A).

\section{Proliferation and biotransformation of normal hepatocytes are induced by rigidity}

To confirm that 3D collagen environment regulates liver-cell fate, we established 3D primary cultures of normal rat and human hepatocytes, a well established model system for studying proliferation and differentiation, in vitro. First, we confirmed the spreading of the cells in compliant gels and showed that primary rat hepatocytes stayed non-spread (round) in rigid gels (figure 7A). Note that normal hepatocytes are non motile cells and never form spherical clusters in 3.5 PA gels. Second, we have extended the positive role of 3D stiffness on cell proliferation (figure 7B) and clearly demonstrated that EGF-stimulated rat hepatocytes in 3D gels replicated at higher level than cells cultured in 2D environment (figure 7B). Moreover, as in Huh7 cells, stiffness clearly greatly increases the proliferative capabilities of normal hepatocytes with a 2 and 4 fold increase of thymidine incorporation in rigid gels as compared to $2 \mathrm{D}$ cultures and compliant gels, respectively.

To ascertain the role of 3D cultures on hepatocyte differentiation, we then tested the expression level of different liver functions by qPCR in primary human hepatocytes. Clearly, albumin, aldolaseB and GSTa2 mRNA expression were highly expressed in 3D compliant and rigid gels as compared to $2 \mathrm{D}$ cultures showing that $3 \mathrm{D}$ environment of the hepatocytes is determinant for keeping human hepatocytes in a more differentiated state (figure 7C). Interestingly, we demonstrated a potentialisation of 3-methyl cholentrene (MC) induction of Cytochrome P450 CYP1A activities (figure 7D and E) as well as CYP1A2 activities (figure 7E) of Huh7 and Human hepatocytes in $3 \mathrm{D}$ rigid gels as compared to $2 \mathrm{D}$ cultures and $3 \mathrm{D}$ compliant gels. 


\section{Discussion:}

In this study, we demonstrated that the proliferation of normal and transformed liver cells embedded in the matrix are highly controlled/induced by 3D force variations indicating that this 3D model is an attractive tool for studying the rigidity-dependent homeostasis of liver cells which occur during fibrosis development. In a constant chemical environment, proliferation rate of normal and transformed hepatocytes are highly induced by rigid matrix whereas in compliant gels liver cells are well spreaded and less proliferative. Moreover, 3D culture models induced a more epithelial phenotype of tranformed liver cells while maintaining long term survival and differentiation of normal rat and human hepatocytes.

Overall, our results concerning the morphology, MET and differentiation markers in 3D matrix showed remarkable differences with previous studies of hepatic cells cultured on collagen gels (Godoy et al., 2009; Schrader et al., 2011). Increased evidence has shown that the mechanical forces of the extracellular matrix are critical for liver cells growth, multi-cellular organisation and motility (Wang et al., 2000; Lutolf and Hubbell, 2005; Grinnell and Petroll, 2010). In vivo studies reported that liver fibrosis could stimulate tumour development of implanted hepatocellular carcinoma cells (Kornek et al., 2008; Yang et al., 2010). Many studies have been done to understand this process using cell culture systems on collagen films and gels. These systems, and particularly the mechanically-tunable coated polyacrylamide gels, bring forth important information about the mechanisms involved in mesenchymal shift and in the regulation of HCC proliferation. On collagen coated polyacrylamide gels, soft substrates resulted in the reduction of proliferation where the cells appeared rounded in contrast to the well-spread and flattened cells on stiff supports (Schrader et al., 2011). Hepatocytes cultured on collagen film or stiff supports have increased DNA synthesis with reduced differentiated functions, whereas cells on soft gels were less proliferative. Nevertheless, hepatic cells cultures on collagen coated polyacrylamide gels do not represent the complex $3 \mathrm{D}$ structure of liver in vivo and cells did not account for the 3D complex organisation of cellular clusters. Many 3D models have been developed which show that three-dimentional cultures of tumour cells could be an attractive tool for toxicological studies showing high cell differentiation and long term survival (Darnell et al., 2012; Gómez-Lechón et al., 1998; Gunness et al., 2013; Kostadinova et al., 2013; Leite et al., 2012; Meli et al., 2012). Within these models, collagen gels show highly uniform and smooth randomly oriented nanofibers, spaced with loose areas between fibrils which allow hepatic cells to be embedded in the gels and to survive for several weeks. Here, we demonstrated that, in a constant growth factor environment, increasing 3D mechanical forces promoted the proliferation of normal and transformed hepatic cells within collagen gels. This effect is associated with 
spheroid formations in stiff gel while cells appear flattened and spread in soft matrices and are less proliferative.

As compared to 2D culture, 3D cultures are also accompanied by a mesemchymal to epithelial like transition (switch): a decreased expression of cytokeratin 8 and 18, N-cadherin, vimentin, and an increase of E-cadherin. Expressions of $\mathrm{N}$ - and E-cadherin showed membrane polarity at the inner/lumen and apical/lateral cell-cell domains of spheroids. Moreover, 3D reconstruction of spheroids in stiff matrices showed that Huh7 assembled in acini of one or two cell layers, with large lumens which increased with time. Normal hepatocytes also are more differentiated in 3D cultures and more proliferative in stiff gels showing that normal hepatic cells can proliferate and be differentiated if $3 \mathrm{D}$ interactions between cells and matrix are still maintained. Higher 3-MC induction of CYP1A2 activities are obtained in human hepatopcytes cultured in rigid gels indicating that cells within collagen matrix could be an easy tool to generate mature hepatocytes that would be applicable for drug toxicity testing and pharmacological long term and chronical studies.

Concerning the proliferation rate, our results point to different 3D cell behaviours between stiff and soft matrices, which can be obtained with a 3.5 fold increase in force variations (between $1 \mathrm{~Pa}$ to $3.5 \mathrm{~Pa}$ ) showing the strong capacity of this model to modulate hepatic cell proliferation. Note that this elastic modulus fold increase is close to the fold increase (x4) measured in liver during fibrosis progression in rat model, from $400 \mathrm{~Pa}$ (normal liver) to 1600 $\mathrm{Pa}$ (after CCl4 treatment) (Georges et al., 2007) and during fibrotic-cirrhotic human liver progression (from $1 \mathrm{KPa}$ to $4 \mathrm{KPa}$ ) (Lupsor Platon et al., 2013). Our results are consistent with the work of Scharder et al. (2011) showing that the proliferative index was higher when hepatic cells were cultured on stiff versus soft supports. Interestingly, $\beta 1$ integrin was found to modulate stiffness-dependent HCC cell proliferation showing that integrin signaling could play a role in behaviour of cultured on collagen. However, in our work, kinetics and levels of ERK1/2 phosphorylations are similar in Huh7 cells cultured in 1 and $3.5 \mathrm{~Pa}$ gels arguing for a possible less role of integrin signaling in the proliferative response during increasing matrix stiffness in cells embedded in 3D gels.

Our results are consistent with in vivo reports which show that: - collagen-dense microenvironment promotes mammary tumor initiation/progression (Provenzano et al., 2008) - induction of liver fibrosis in murine hepatoma model is associated with enhanced tumor growth (Yang et al., 2010) - liver fibrosis stimulates tumour development and advanced tumor spread of implanted syngenic hepatoma cells (Kornek et al., 2008).

The MEK/ERK pathway is required for proliferation of hepatocarcinoma cells and this regulation in hepatic tumoral cells could occur via an ERK2 dependent mechanism. The strict specificity of action of the MAPKs is still debated and the different levels of expression of 
ERK1 and ERK2 could take into account the apparent specificity of the MAPK (Lefloch et al., 2008). Data could suggest specialized functions of ERK1 and ERK2 in differentiated cells such as hepatic cells. As already demonstrated in 2D normal (Frémin et al., 2012, 2009, 2007) and transfomed hepatic cells (Bessard et al., 2008; Gailhouste et al., 2010), our data in $3 \mathrm{D}$ embedded cells confirmed that ERK2 is involved in the regulation of proliferation, whereas ERK1 could be a regulator of apoptosis induced by cisplatin. In vivo, production of Col I during liver fibrosis induces a hepatoprotective response that is mediated by activation of ERK1 signaling (Bourbonnais et al., 2012). We recently demonstrated, using the livers of ERK1-deficient mice, that ERK1 silencing alone is sufficient to protect cells from cisplatininduced death both in vitro, in ERK1-/- normal hepatocytes, and in vivo (Guégan et al., 2013). Furthermore, in wt cell, this regulation is also highly influenced by ERK2 inhibition, since a balance of phophorylation between the two MAPK has been reported in many cell types and silencing ERK2 are accompagnied by an increased level of ERK1 phosphorylation (Bessard et al., 2008; Frémin et al., 2009, 2007; Gailhouste et al., 2010; Lefloch et al., 2008).

Cells embedded in collagen matrix are a powerful model for studying in vitro the dynamic response to stiffness variations in well differentiated liver cells in a $3 \mathrm{D}$ environment. Collagen gels with varying forces will be useful and pertinent models to study proliferation of both long term normal and transformed liver cells and to screen drugs and therapeutic agents that could interfere with the regulation of proliferation of tumoral hepatic cells. 


\section{Acknowledgements:}

The authors thank Transant (Lyon, France) and the "Ligue Nationale Contre le Cancer" for providing human shRNAs. We thank Dr Christophe Lanos for rheometry assays and Marc Le Vee for rat hepatocytes isolation by perfusion. We thank platforms PIXEL, MRic-Photonics, H2P2, Human CRB and animal facilities ARCHE (SFR Biosit, UMS CNRS 3480 / US INSERM 018, Rennes). 


\section{Bibliography:}

Andrieux, L., Langouët, S., Fautrel, A., Ezan, F., Krauser, J.A., Savouret, J.F., Guengerich, F.P., Baffet, G., Guillouzo, A., 2004. Aryl Hydrocarbon Receptor Activation and Cytochrome P450 1A Induction by the Mitogen-Activated Protein Kinase Inhibitor U0126 in Hepatocytes. Mol. Pharmacol. 65, 934-943. doi:10.1124/mol.65.4.934

Baffet, G., Loyer, P., Glaise, D., Corlu, A., Etienne, P.L., Guguen-Guillouzo, C., 1991. Distinct effects of cell-cell communication and corticosteroids on the synthesis and distribution of cytokeratins in cultured rat hepatocytes. J. Cell Sci. 99 ( Pt 3), 609-615.

Bessard, A., Frémin, C., Ezan, F., Coutant, A., Baffet, G., 2007. MEK/ERK-dependent uPAR expression is required for motility via phosphorylation of P70S6K in human hepatocarcinoma cells. J. Cell. Physiol. 212, 526-536. doi:10.1002/jcp.21049

Bessard, A., Frémin, C., Ezan, F., Fautrel, A., Gailhouste, L., Baffet, G., 2008. RNAimediated ERK2 knockdown inhibits growth of tumor cells in vitro and in vivo. Oncogene 27, 5315-5325. doi:10.1038/onc.2008.163

Bourbonnais, E., Raymond, V.-A., Ethier, C., Nguyen, B.N., El-Leil, M.S., Meloche, S., Bilodeau, M., 2012. Liver fibrosis protects mice from acute hepatocellular injury. Gastroenterology 142, 130-139.e4. doi:10.1053/j.gastro.2011.09.033

Burke, M.D., Mayer, R.T., 1983. Differential effects of phenobarbitone and 3methylcholanthrene induction on the hepatic microsomal metabolism and cytochrome P-450-binding of phenoxazone and a homologous series of its n-alkyl ethers (alkoxyresorufins). Chem. Biol. Interact. 45, 243-258.

Campagnola, P.J., Millard, A.C., Terasaki, M., Hoppe, P.E., Malone, C.J., Mohler, W.A., 2002. Three-Dimensional High-Resolution Second-Harmonic Generation Imaging of Endogenous Structural Proteins in Biological Tissues. Biophys. J. 82, 493-508. doi:10.1016/S0006-3495(02)75414-3

Chen, X., Nadiarynkh, O., Plotnikov, S., Campagnola, P.J., 2012. Second harmonic generation microscopy for quantitative analysis of collagen fibrillar structure. Nat. Protoc. 7, 654-669. doi:10.1038/nprot.2012.009

Darnell, M., Ulvestad, M., Ellis, E., Weidolf, L., Andersson, T.B., 2012. In vitro evaluation of major in vivo drug metabolic pathways using primary human hepatocytes and HepaRG cells in suspension and a dynamic three-dimensional bioreactor system. J. Pharmacol. Exp. Ther. 343, 134-144. doi:10.1124/jpet.112.195834

Frémin, C., Bessard, A., Ezan, F., Gailhouste, L., Régeard, M., Le Seyec, J., Gilot, D., Pagès, G., Pouysségur, J., Langouët, S., Baffet, G., 2009. Multiple division cycles and longterm survival of hepatocytes are distinctly regulated by extracellular signal-regulated kinases ERK1 and ERK2. Hepatol. Baltim. Md 49, 930-939. doi:10.1002/hep.22730

Frémin, C., Ezan, F., Boisselier, P., Bessard, A., Pagès, G., Pouysségur, J., Baffet, G., 2007. ERK2 but not ERK1 plays a key role in hepatocyte replication: an RNAi-mediated ERK2 knockdown approach in wild-type and ERK1 null hepatocytes. Hepatol. Baltim. Md 45, 1035-1045. doi:10.1002/hep.21551

Frémin, C., Ezan, F., Guegan, J.-P., Gailhouste, L., Trotard, M., Le Seyec, J., Rageul, J., Theret, N., Langouët, S., Baffet, G., 2012. The complexity of ERK1 and ERK2 MAPKs in multiple hepatocyte fate responses. J. Cell. Physiol. 227, 59-69. doi:10.1002/jcp.22742

Gailhouste, L., Ezan, F., Bessard, A., Frémin, C., Rageul, J., Langouët, S., Baffet, G., 2010. RNAi-mediated MEK1 knock-down prevents ERK1/2 activation and abolishes human hepatocarcinoma growth in vitro and in vivo. Int. J. Cancer J. Int. Cancer 126, 13671377. doi:10.1002/ijc. 24950

Gauderon, R., Lukins, P.B., Sheppard, C.J., 2001a. Optimization of second-harmonic generation microscopy. Micron Oxf. Engl. 1993 32, 691-700.

Gauderon, R., Lukins, P.B., Sheppard, C.J., 2001b. Simultaneous multichannel nonlinear imaging: combined two-photon excited fluorescence and second-harmonic generation microscopy. Micron Oxf. Engl. 1993 32, 685-689. 
Georges, P.C., Hui, J.-J., Gombos, Z., McCormick, M.E., Wang, A.Y., Uemura, M., Mick, R., Janmey, P.A., Furth, E.E., Wells, R.G., 2007. Increased stiffness of the rat liver precedes matrix deposition: implications for fibrosis. Am. J. Physiol. Gastrointest. Liver Physiol. 293, G1147-1154. doi:10.1152/ajpgi.00032.2007

Godoy, P., Hengstler, J.G., Ilkavets, I., Meyer, C., Bachmann, A., Müller, A., Tuschl, G., Mueller, S.O., Dooley, S., 2009. Extracellular matrix modulates sensitivity of hepatocytes to fibroblastoid dedifferentiation and transforming growth factor betainduced apoptosis. Hepatol. Baltim. Md 49, 2031-2043. doi:10.1002/hep.22880

Gómez-Lechón, M.J., Jover, R., Donato, T., Ponsoda, X., Rodriguez, C., Stenzel, K.G., Klocke, R., Paul, D., Guillén, I., Bort, R., Castell, J.V., 1998. Long-term expression of differentiated functions in hepatocytes cultured in three-dimensional collagen matrix. J. Cell. Physiol. 177, 553-562. doi:10.1002/(SICI)10974652(199812)177:4<553::AID-JCP6>3.0.CO;2-F

Grinnell, F., Petroll, W.M., 2010. Cell motility and mechanics in three-dimensional collagen matrices. Annu. Rev. Cell Dev. Biol. 26, 335-361. doi:10.1146/annurev.cellbio.042308.113318

Guégan, J.-P., Ezan, F., Théret, N., Langouët, S., Baffet, G., 2013. MAPK signaling in cisplatin-induced death: predominant role of ERK1 over ERK2 in human hepatocellular carcinoma cells. Carcinogenesis 34, 38-47. doi:10.1093/carcin/bgs317

Guégan, J.-P., Frémin, C., Baffet, G., 2012. The MAPK MEK1/2-ERK1/2 Pathway and Its Implication in Hepatocyte Cell Cycle Control. Int. J. Hepatol. 2012, 328372. doi:10.1155/2012/328372

Guguen-Guillouzo, C., 2002. Isolation and Culture of Animal and Human Hepatocytes, in: Freshney, R.I., Freshney, ry G. (Eds.), Culture of Epithelial Cells. John Wiley \& Sons, Inc., pp. 337-379.

Gunness, P., Mueller, D., Shevchenko, V., Heinzle, E., Ingelman-Sundberg, M., Noor, F., 2013. 3D organotypic cultures of human HepaRG cells: a tool for in vitro toxicity studies. Toxicol. Sci. Off. J. Soc. Toxicol. 133, 67-78. doi:10.1093/toxsci/kft021

Hansen, L.K., Wilhelm, J., Fassett, J.T., 2006. Regulation of hepatocyte cell cycle progression and differentiation by type I collagen structure. Curr. Top. Dev. Biol. 72, 205-236. doi:10.1016/S0070-2153(05)72004-4

Kholodenko, B.N., Hancock, J.F., Kolch, W., 2010. Signalling ballet in space and time. Nat. Rev. Mol. Cell Biol. 11, 414-426. doi:10.1038/nrm2901

König, K., 2000. Multiphoton microscopy in life sciences. J. Microsc. 200, 83-104.

Kornek, M., Raskopf, E., Tolba, R., Becker, U., Klöckner, M., Sauerbruch, T., Schmitz, V., 2008. Accelerated orthotopic hepatocellular carcinomas growth is linked to increased expression of pro-angiogenic and prometastatic factors in murine liver fibrosis. Liver Int. Off. J. Int. Assoc. Study Liver 28, 509-518. doi:10.1111/j.14783231.2008.01670.x

Kostadinova, R., Boess, F., Applegate, D., Suter, L., Weiser, T., Singer, T., Naughton, B., Roth, A., 2013. A long-term three dimensional liver co-culture system for improved prediction of clinically relevant drug-induced hepatotoxicity. Toxicol. Appl. Pharmacol. 268, 1-16. doi:10.1016/j.taap.2013.01.012

Lee, U.E., Friedman, S.L., 2011. Mechanisms of Hepatic Fibrogenesis. Best Pract. Res. Clin. Gastroenterol. 25, 195-206. doi:10.1016/j.bpg.2011.02.005

Lefloch, R., Pouysségur, J., Lenormand, P., 2008. Single and combined silencing of ERK1 and ERK2 reveals their positive contribution to growth signaling depending on their expression levels. Mol. Cell. Biol. 28, 511-527. doi:10.1128/MCB.00800-07

Leite, S.B., Wilk-Zasadna, I., Zaldivar, J.M., Airola, E., Reis-Fernandes, M.A., Mennecozzi, M., Guguen-Guillouzo, C., Chesne, C., Guillou, C., Alves, P.M., Coecke, S., 2012. Three-dimensional HepaRG model as an attractive tool for toxicity testing. Toxicol. Sci. Off. J. Soc. Toxicol. 130, 106-116. doi:10.1093/toxsci/kfs232

Lupsor Platon, M., Stefanescu, H., Feier, D., Maniu, A., Badea, R., 2013. Performance of unidimensional transient elastography in staging chronic hepatitis $\mathrm{C}$. Results from a 
cohort of 1,202 biopsied patients from one single center. J. Gastrointest. Liver Dis. JGLD 22, 157-166.

Lutolf, M.P., Hubbell, J.A., 2005. Synthetic biomaterials as instructive extracellular microenvironments for morphogenesis in tissue engineering. Nat. Biotechnol. 23, 4755. doi:10.1038/nbt1055

Masuzaki, R., Tateishi, R., Yoshida, H., Goto, E., Sato, T., Ohki, T., Imamura, J., Goto, T., Kanai, F., Kato, N., Ikeda, H., Shiina, S., Kawabe, T., Omata, M., 2009. Prospective risk assessment for hepatocellular carcinoma development in patients with chronic hepatitis C by transient elastography. Hepatology 49, 1954-1961. doi:10.1002/hep.22870

Meli, L., Jordan, E.T., Clark, D.S., Linhardt, R.J., Dordick, J.S., 2012. Influence of a threedimensional, microarray environment on human cell culture in drug screening systems. Biomaterials 33, 9087-9096. doi:10.1016/j.biomaterials.2012.08.065

Moll, R., Franke, W.W., Schiller, D.L., Geiger, B., Krepler, R., 1982. The catalog of human cytokeratins: patterns of expression in normal epithelia, tumors and cultured cells. Cell 31, 11-24.

Morel-Chany, E., Guillouzo, C., Trincal, G., Szajnert, M.F., 1978. "Spontaneous" neoplastic transformation in vitro of epithelial cell strains of rat liver: cytology, growth and enzymatic activities. Eur. J. Cancer 14, 1341-1352.

Paszek, M.J., Weaver, V.M., 2004. The tension mounts: mechanics meets morphogenesis and malignancy. J. Mammary Gland Biol. Neoplasia 9, 325-342. doi:10.1007/s10911004-1404-X

Paszek, M.J., Zahir, N., Johnson, K.R., Lakins, J.N., Rozenberg, G.I., Gefen, A., ReinhartKing, C.A., Margulies, S.S., Dembo, M., Boettiger, D., Hammer, D.A., Weaver, V.M., 2005. Tensional homeostasis and the malignant phenotype. Cancer Cell 8, 241-254. doi:10.1016/j.ccr.2005.08.010

Provenzano, P.P., Inman, D.R., Eliceiri, K.W., Knittel, J.G., Yan, L., Rueden, C.T., White, J.G., Keely, P.J., 2008. Collagen density promotes mammary tumor initiation and progression. BMC Med. 6, 11. doi:10.1186/1741-7015-6-11

Schrader, J., Gordon-Walker, T.T., Aucott, R.L., van Deemter, M., Quaas, A., Walsh, S., Benten, D., Forbes, S.J., Wells, R.G., Iredale, J.P., 2011. Matrix stiffness modulates proliferation, chemotherapeutic response, and dormancy in hepatocellular carcinoma cells. Hepatol. Baltim. Md 53, 1192-1205. doi:10.1002/hep.24108

Wallace, K., Burt, A.D., Wright, M.C., 2008. Liver fibrosis. Biochem. J. 411, 1-18. doi:10.1042/BJ20071570

Wang, H.B., Dembo, M., Wang, Y.L., 2000. Substrate flexibility regulates growth and apoptosis of normal but not transformed cells. Am. J. Physiol. Cell Physiol. 279, C1345-1350.

Yang, M.-C., Chang, C.-P., Lei, H.-Y., 2010. Induction of liver fibrosis in a murine hepatoma model by thioacetamide is associated with enhanced tumor growth and suppressed antitumor immunity. Lab. Investig. J. Tech. Methods Pathol. 90, 1782-1793. doi:10.1038/labinvest.2010.139

Zipfel, W.R., Williams, R.M., Webb, W.W., 2003. Nonlinear magic: multiphoton microscopy in the biosciences. Nat. Biotechnol. 21, 1369-1377. doi:10.1038/nbt899 


\section{Figure Legends}

Figure 1: Increased collagen gel concentration induces 3D stiffness. A. Visualization by SHG microscopy of collagen network of gels from 0.25 to $2 \mathrm{mg} / \mathrm{ml}$ of collagen (scale bar: $50 \mu \mathrm{m})$. B. 3D SHG microscopy representation of 1 and $1.5 \mathrm{mg} / \mathrm{ml}$ collagen gels. C. SHG image analysis: collagen area (percentage), pore area, fiber length and fiber diameter. $\mathbf{D}$. Collagen gel stiffness measured by rheometry with an oscillatory frequency of $0.1 \mathrm{~Hz}$. Graphical representations of the viscous and elastic modulus as a function of the collagen concentrations. (Mean \pm SD)

Figure 2: Matrix rigidity influences spheroid formation of human Huh7 hepatocellular carcinoma cells. A. Phase contrast micrographs of Huh7 cells after 3 days of culture in $1 \mathrm{~Pa}$ and 3.5Pa collagen gels. B. TPEF images after DiA staining of Huh7 cells at 3, 6 or 10 days of culture in $1 \mathrm{~Pa}$ and $3.5 \mathrm{~Pa}$ collagen gels. Left images represent a $2 \mu \mathrm{m}$ section of the gels

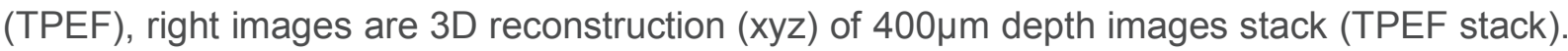
C. Confocal images after staining with Phalloidin and Hoechst, at 1 and 8 days of culture in $1 \mathrm{~Pa}$ and 3.5Pa collagen gels: confocal images (left) and 3D reconstructions (right). Scale bar: $50 \mu \mathrm{m}$.

Figure 3: Cluster organisation and cell plasticity. A. TPEF 3D images reconstruction after Hoechst and Paxillin staining of cells after 6 days of culture in $3.5 \mathrm{~Pa}$ collagen gel and merge image. B. Hematoxylin-Eosin staining after paraffin inclusion and observation with slide scanner. C. The $1 \mathrm{~Pa}$ and $3.5 \mathrm{~Pa}$ gels were observed at day 6 of culture (unreleased gels: a and b) and then released from the plastic dishes and observed two days thereafter (released gels: c and d) allowing gels and cells remodeling or not.

Figure 4: Rigidity increases proliferation. Kinetics of MTT assays (A) and Thymidine incorporations (B) during the culture time of Huh7 cells in $1 \mathrm{~Pa}$ and $3.5 \mathrm{~Pa}$ collagen gels. (C and D) The Growth rates of Huh7 cells inhibited or not by a treatment with the MEK inhibitor U0126 $(20 \mu \mathrm{M})$ or stably knocked-down for ERK1 or ERK2 were assessed at each indicated day by MTT assays. Western Blot controls of Phospho-ERK (upper figures $C$ and D). (Mean $\left.\left.\pm \mathrm{SD} ; \mathrm{P}<0.05\left(^{*}\right), \mathrm{P}<0.01\left(^{* *}\right), \mathrm{P}<0.005^{* * *}\right)\right)$

Figure 5: Necrotic and apoptotic activities in 3D cultures. A. For necrotic studies Huh7 cells are stained with Hoechst and Propidium iodide, after 1 and 8 days of culture in 1 and $3.5 \mathrm{~Pa}$ gels. B. Apoptosis of Huh7 cells is determined by caspase $3 / 7$ activities by DEVD-AMC assays after 1,4 and 8 days of $2 \mathrm{D}$ and $3 \mathrm{D}$ cultures. [2D D8+Cis ] is a $2 \mathrm{D}$ control cells treated 
with cisplatin $(10 \mu \mathrm{g} / \mathrm{ml})$. C. Caspase 3/7 activity levels in 2D and 3D Huh7 cells treated with 1 or $10 \mu \mathrm{g} / \mathrm{ml}$ of cisplatin during $24 \mathrm{~h}$ after 1,4 and 8 days of culture. D. Caspase $3 / 7$ activity levels in 3D Huh7 cells after 8 days of 3D cultures treated with a concentration range of cisplatin $(5$ to $30 \mu \mathrm{g} / \mathrm{ml})$ during $24 \mathrm{~h}$. E. Caspase $3 / 7$ activity levels in Huh7 cells after 8 days of culture, treated or not with U0126 and two concentrations of cisplatin (10 and $20 \mu \mathrm{g} / \mathrm{ml}$ ) during 24h. F. Caspase 3/7 activities in Huh7 cells transfected with sh-RNA against ERK1 or ERK2 and treated or not with $40 \mu \mathrm{g} / \mathrm{ml}$ of cisplatin during $24 \mathrm{~h}, 3$ days after transfections. $\left(\right.$ Mean $\pm S D ; P<0.05\left(^{*}\right), P<0.01\left(^{* *}\right), P<0.005\left(^{* * *}\right)$ )

Figure 6: 3D Matrix induces MET-like transition. A. qPCR analysis of N-cadherin, E-cadherin, Vimentin, Cytokeratin 8 and Cytokeratin 18 mRNA expression after 4 and 8 days of 3D Huh7 cultures $(1 \mathrm{~Pa}$ and $3.5 \mathrm{~Pa})$ as compared to $2 \mathrm{D}$ culture. B. Western blot analysis of Vimentin and E-cadherin expression by Huh7 cells after 4 and 8 days of cultures $(2 \mathrm{D}, 1 \mathrm{~Pa}$ and 3.5Pa). Vimentin and E-cadherin expressions in 3D cells were evaluated by densitometry analysis and results expressed as expressions according to the 2D culture. C. Immunostaining of Ecadherin, N-cadherin and Vimentin after 6 days of 3.5 Pa 3D Huh7 cultures.

Figure 7: Proliferation and biotransformation of normal hepatocytes are induced by 3D rigidity. A. Phase contrast micrographs (upper) and TPEF images (lower) of rat hepatocytes cultured in 3D collagen gels for 4 days. B. Thymidine incorporation in 3D normal rat hepatocytes as compared to $2 \mathrm{D}$ cultures, at the indicated times after seeding. C. Albumin, Aldolase and GSTa2 mRNA expressions after 4 days of normal rat hepatocytes in 3D collagen gels and 2D culture. D. EROD-CYP1A activity of Huh7 cells after induction with 3$\mathrm{MC}(0.5 \mu \mathrm{M}$ or $1 \mu \mathrm{M})$ during $24 \mathrm{~h}$ after 4 days of culture (Mean $\pm \mathrm{SD} ; \mathrm{P}<0.05\left({ }^{*}\right), \mathrm{P}<0.01\left(^{* *}\right)$, $\mathrm{P}<0.005\left(^{* * *}\right)$ ). E. CYP1A and CYP1A2 activities (EROD and MROD) of 3D Human hepatocytes after $3-\mathrm{MC}(1 \mu \mathrm{M})$ induction during $24 \mathrm{~h}$ after 4 days of $2 \mathrm{D}$ and $3 \mathrm{D}(1 \mathrm{~Pa}$ and 3.5 $\mathrm{Pa}$ ) primary cultures.

Supplemental Figure 1: A. Values of elastic and viscous moduli in function of collagen concentrations. B. Quantification of Huh7 cell area (phalloïdin) normalized by nuclei numbers and quantification of nuclei area after 1 and 8 days of culture in $1 \mathrm{~Pa}$ and $3.5 \mathrm{~Pa}$ gels. $\mathbf{C}$. Quantification of cell-mediated contraction of $1 \mathrm{~Pa}$ and 3.5 $\mathrm{Pa}$ gels after releasing from the plastic dishes at day 6 (D0) and at the indicated days after releasing (D1 to D6).

Supplemental Figure 2: A. Phospho-ERK activation in 3D Huh7 cells after stimulation by SVF $(10 \%)$ and EGF $(100 \mathrm{ng} / \mathrm{ml})$ and analyzed at the indicated times after stimulation. B. 
Expressions of pro-apoptotic factors Noxa, Bid, Bak, Bax were analyzed after 24h of treatment with cisplatin $(10 \mu \mathrm{M})$ in 3D Huh7 cells stably silenced for ERK1 or ERK2. 
Figure 1

A

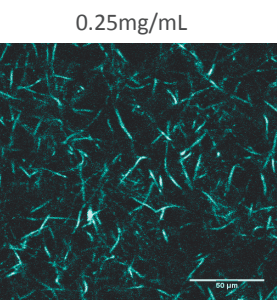

$0.75 \mathrm{mg} / \mathrm{mL}$

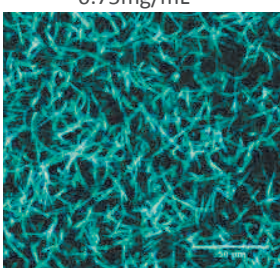

$1.5 \mathrm{mg} / \mathrm{mL}$

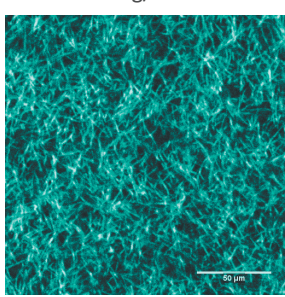

D
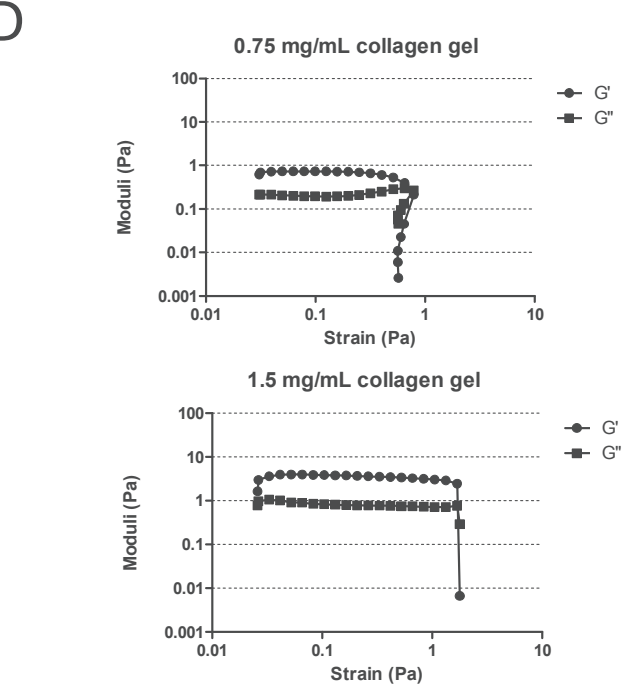

$1 \mathrm{mg} / \mathrm{mL}$

$2 \mathrm{mg} / \mathrm{mL}$
B
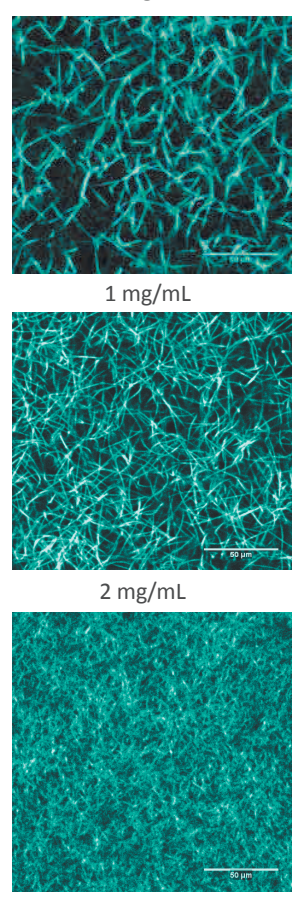

C

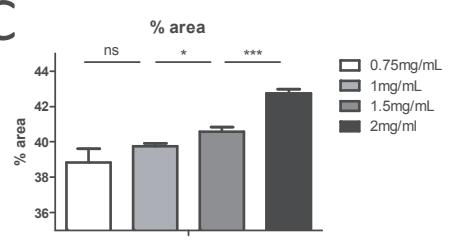

Fiber length
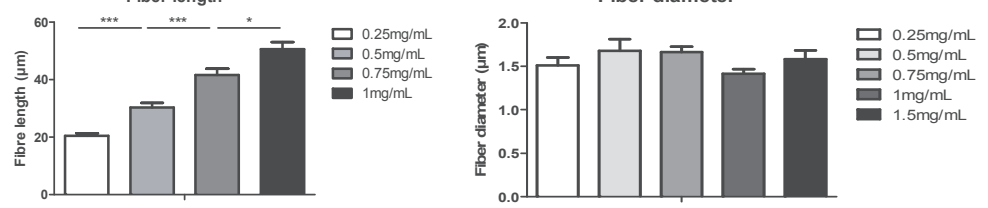

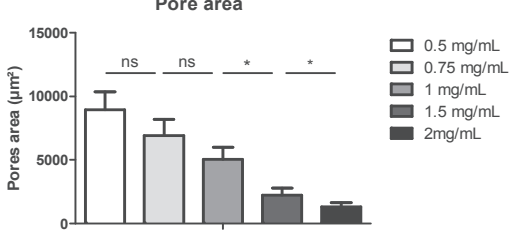

Fiber diameter

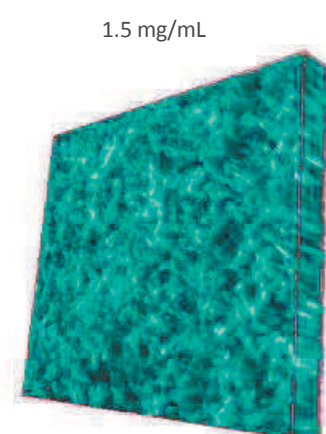

Pore area

$0.75 \mathrm{mg} / \mathrm{m}$

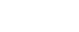

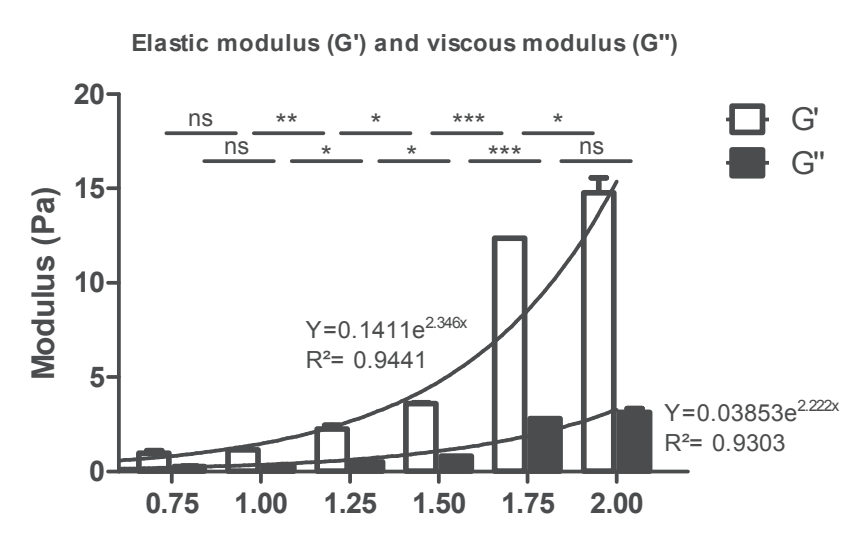


Figure 2

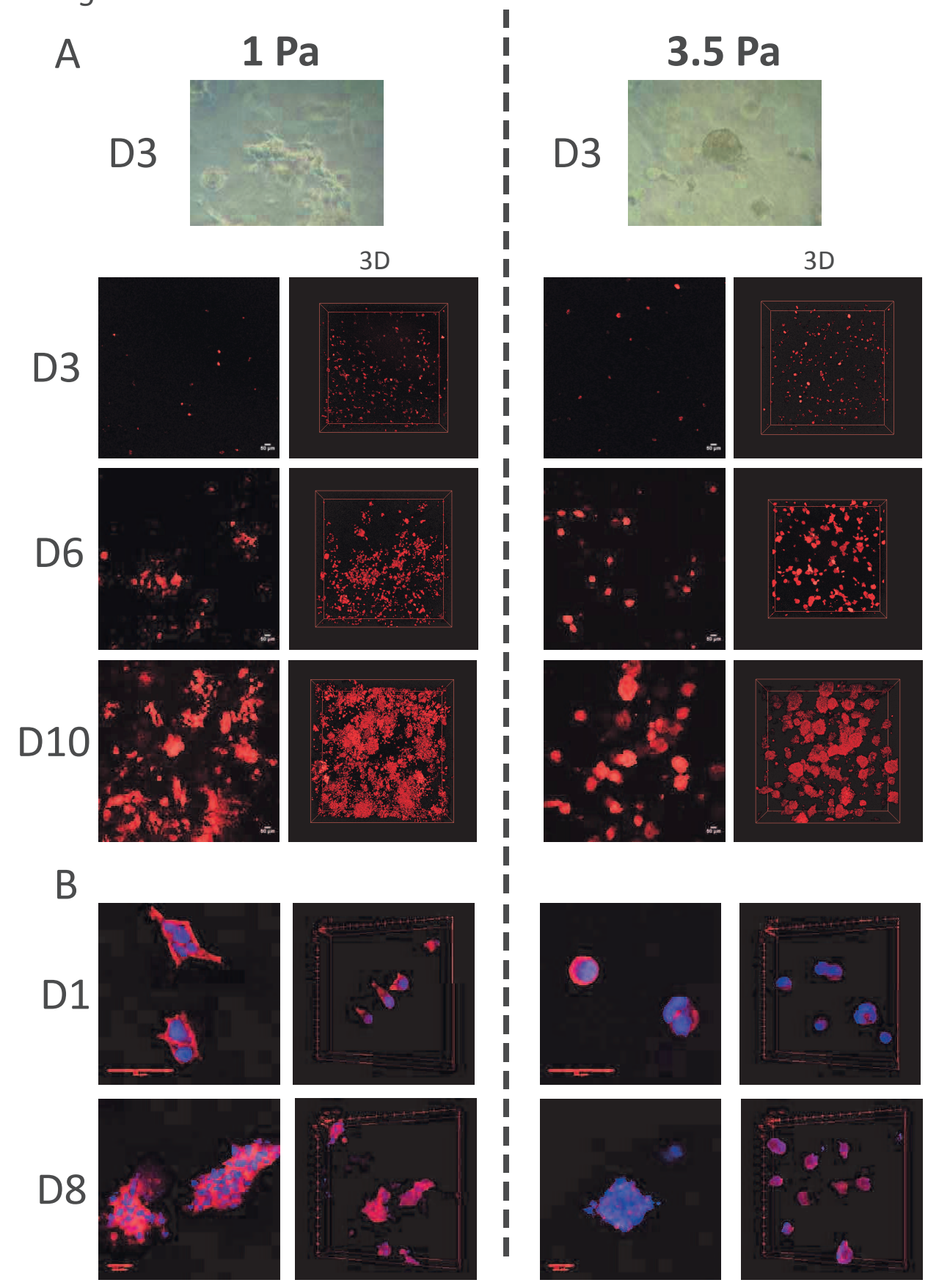


Figure 3

A
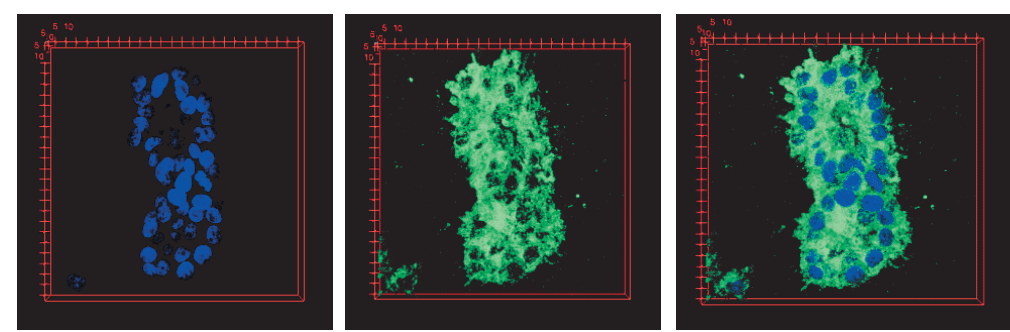

B

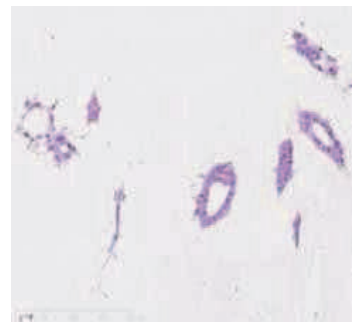

C

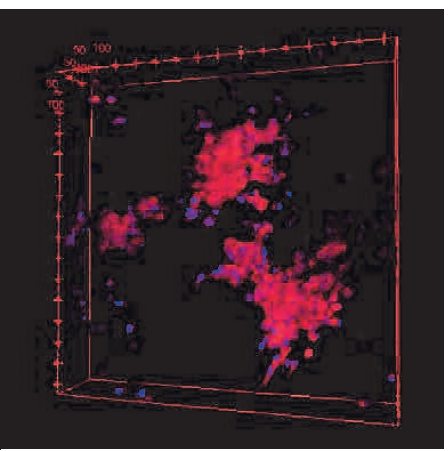

a

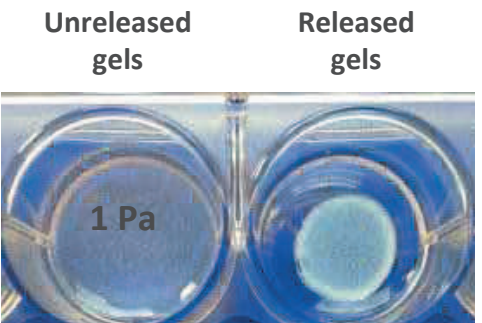

C
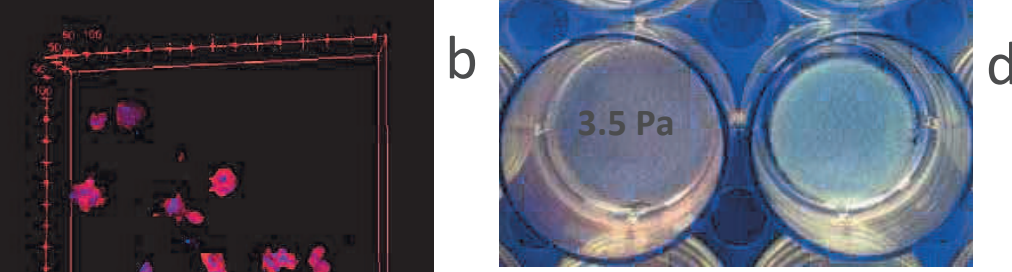
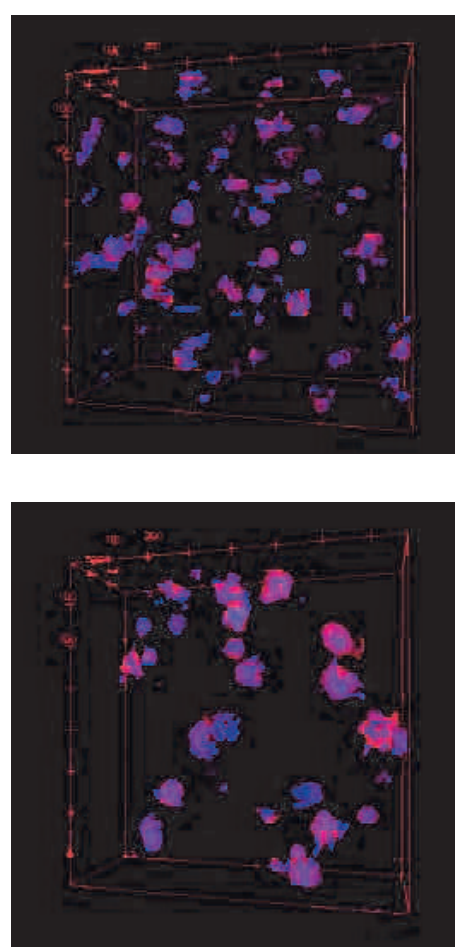
Figure 4

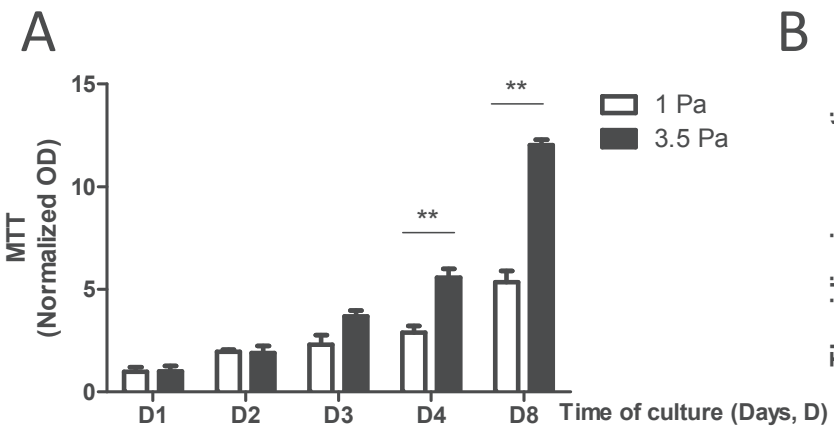

C

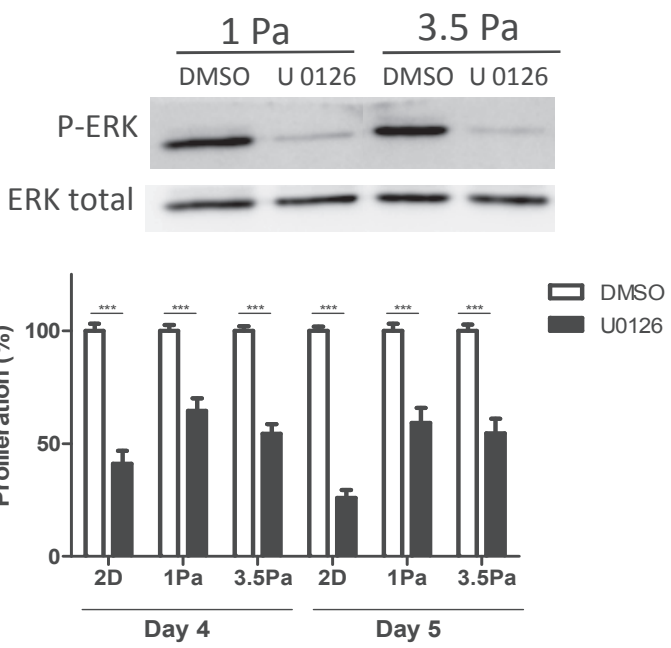

B

D
Bomo et al.
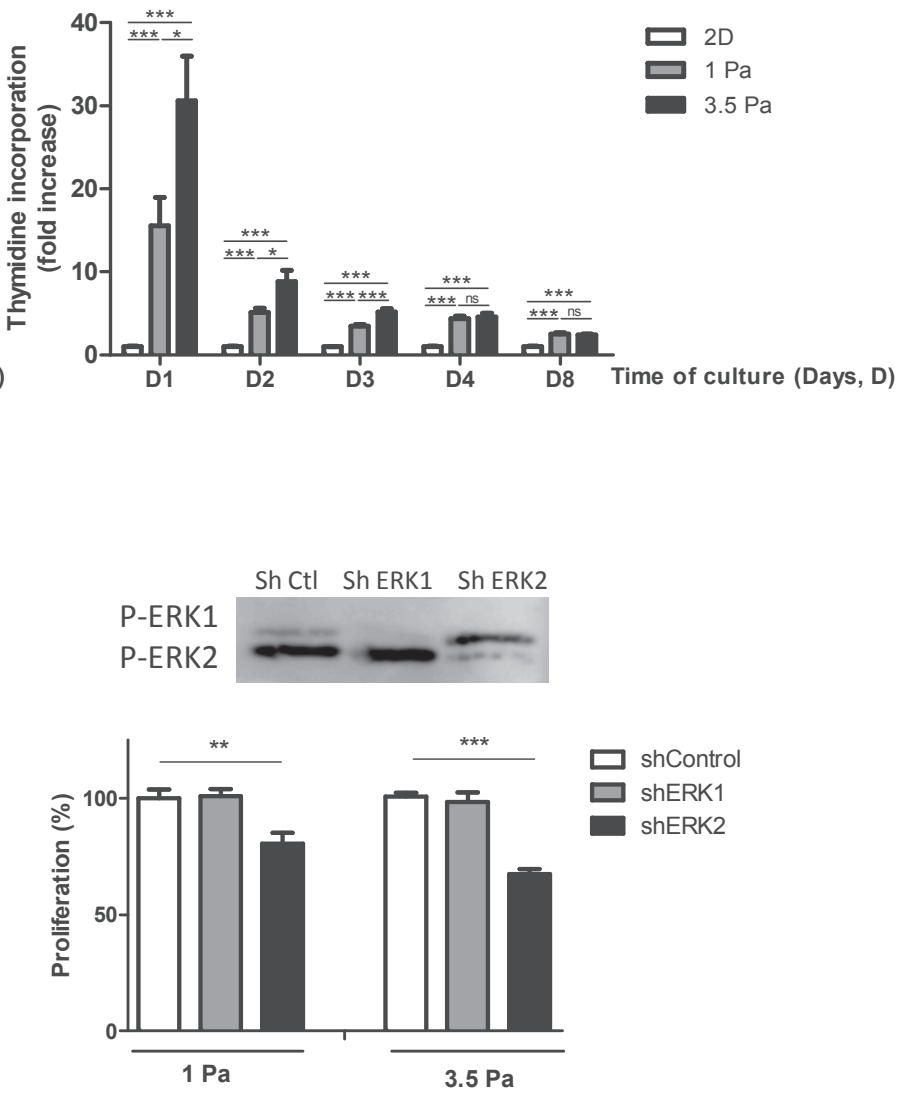
Figure 5

Bomo et al.

A

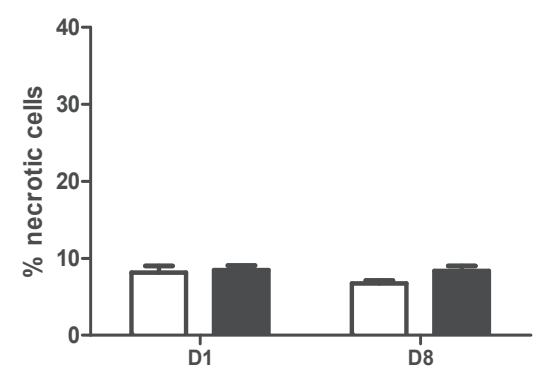

C

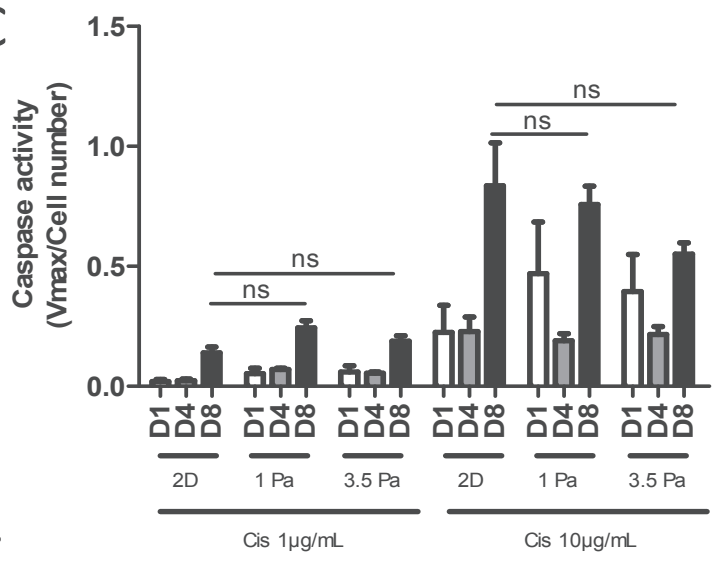

E

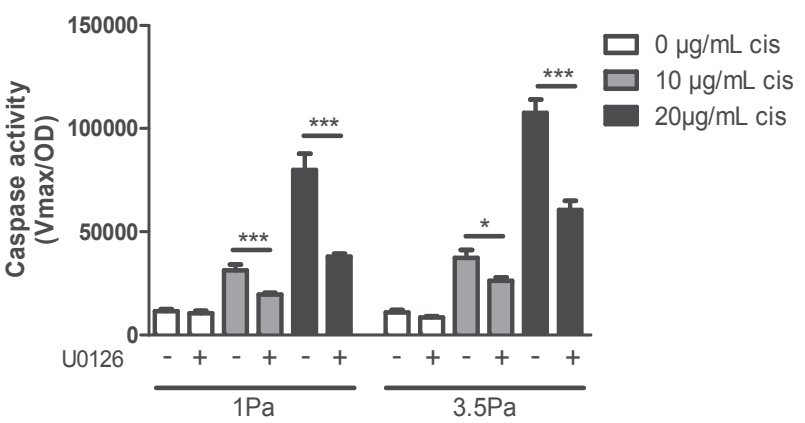

B

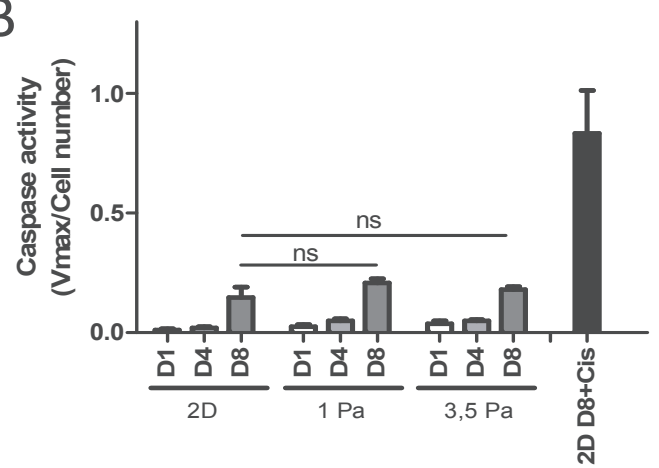

D

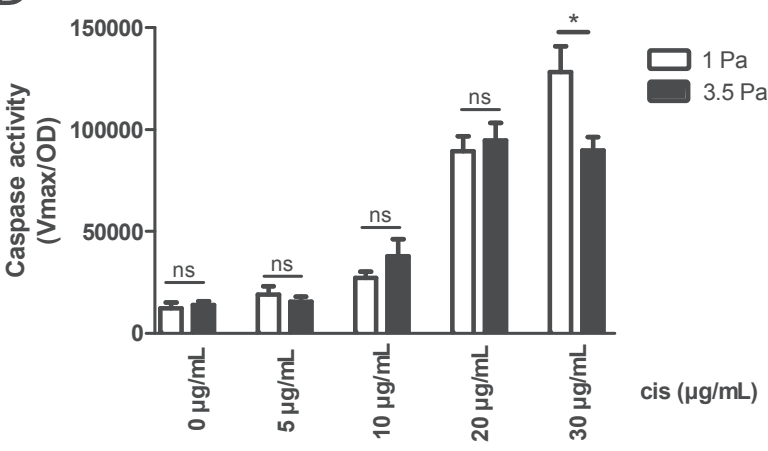

F

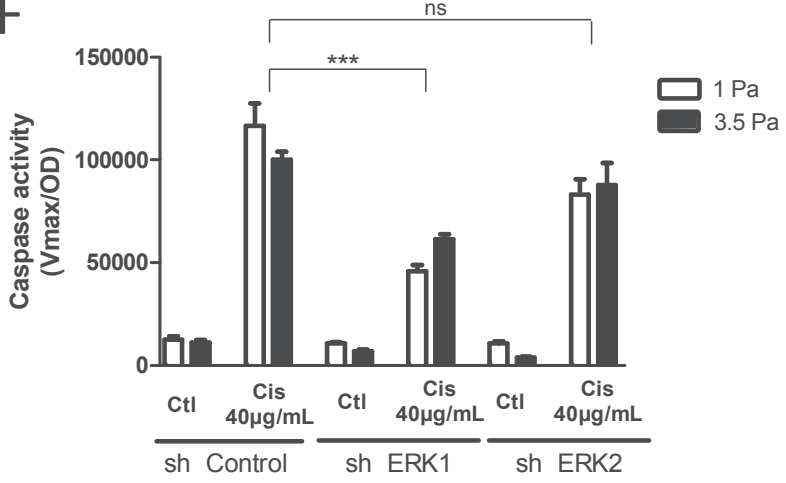


Figure 6

Bomo et al.

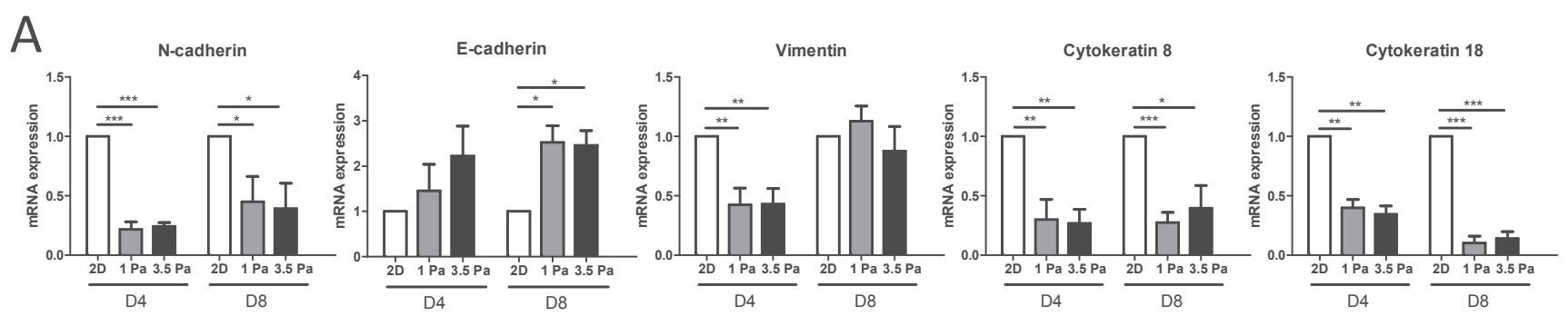

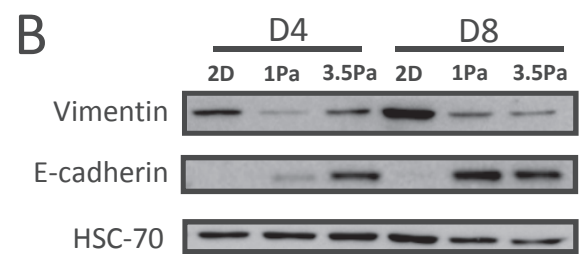

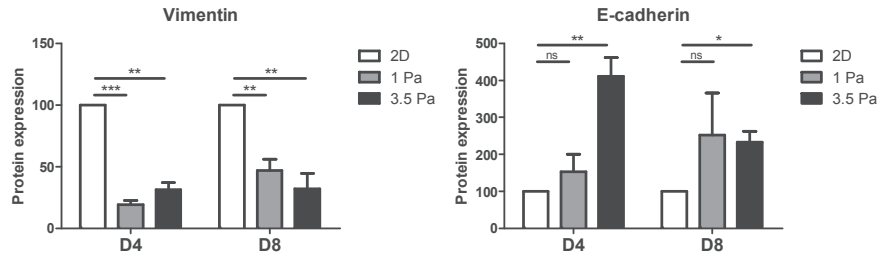

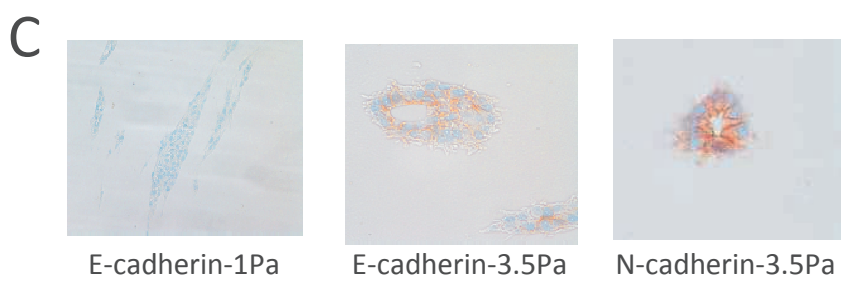

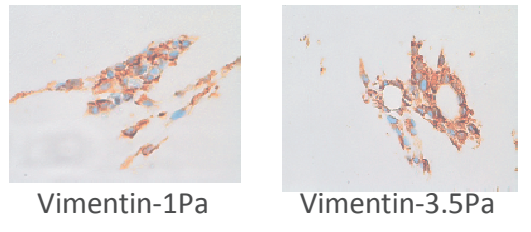


Figure 7

Bomo et al.

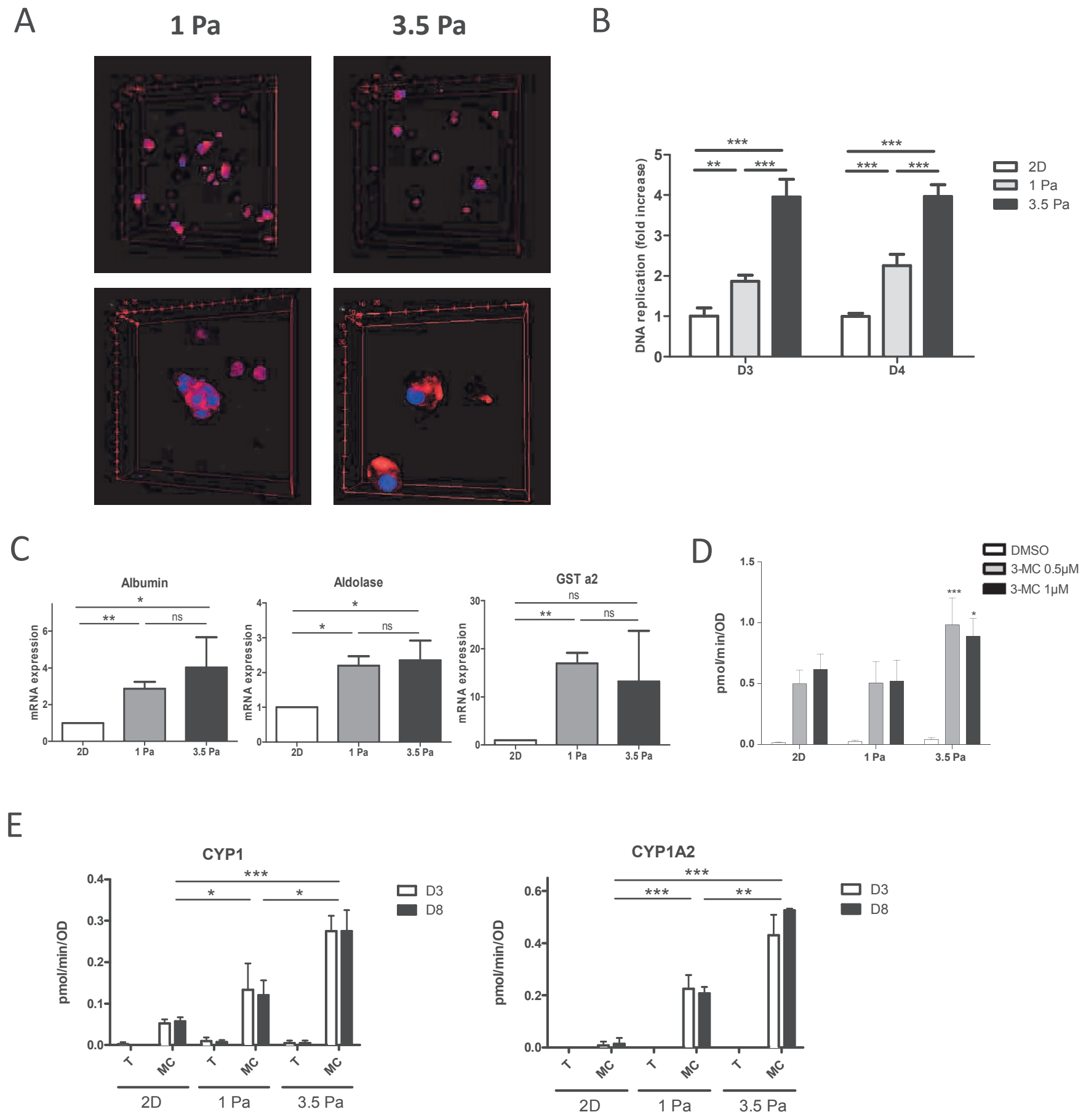

